\title{
A Comparison of the Effectiveness of Cysteamine and Phosphocysteamine in Elevating Plasma Cysteamine Concentration and Decreasing Leukocyte Free Cystine in Nephropathic Cystinosis
}

\author{
LORI A. SMOLIN, KAREN F. CLARK, JESS G. THOENE, WILLIAM A. GAHL, AND \\ JERRY A. SCHNEIDER \\ Department of Pediatrics, School of Medicine, University of California, San Diego, La Jolla, California 92093; \\ Department of Pediatrics, School of Public Health, University of Michigan, Ann Arbor, Michigan 48109; and \\ Section on Human Biochemical Genetics, Human Genetics Branch, National Institute of Child Health and \\ Human Development, National Institutes of Health, Bethesda, Maryland 20892
}

\begin{abstract}
Cysteamine ( $\beta$-mercaptoethylamine, MEA) is currently used to treat children with nephropathic cystinosis. In this study MEA was compared to phosphocysteamine (MEAP), a phosphorothioester that tastes and smells better than MEA, with respect to its ability to elevate plasma MEA and deplete leukocytes of cystine. Studies were performed in six children with nephropathic cystinosis ranging in age from 2 to $10 \mathrm{yr}$. After equimolar oral doses of either MEA or MEAP plasma cysteamine was determined at various times for $6 \mathrm{~h}$. MEA was determined by sodium borohydride reduction followed by highperformance liquid chromatography separation and electrochemical detection. Leukocyte cystine was measured before and 1 and $6 \mathrm{~h}$ after drug administration. Peak plasma MEA was obtained $30 \mathrm{~min}$ to $1 \mathrm{~h}$ after a dose and was not significantly different when MEA $(48.6 \pm 10.7$, mean \pm SD) or MEAP $(54.1 \pm 20.2)$ was given. Significant plasma MEA concentrations were seen as early as $15 \mathrm{~min}$ after an oral dose, indicating rapid absorption. Analysis of vomitus indicated that hydrolysis of the phosphate group of MEAP occurs in the stomach. The percent decrease in leukocyte cystine content obtained with MEA administration $(61.9 \%$ ) was not significantly different from the decrease observed when MEAP was administered $(65.3 \%)$. MEA and MEAP appear to be equally effective in their cystine-depleting properties. (Pediatr Res 23: 616-620, 1988)
\end{abstract}

\section{Abbreviations}

MEA, cysteamine

MEAP, phosphocysteamine

MEA ( $\beta$-mercaptoethylamine) has been used since 1979 as a part of a national collaborative study to treat children with

Received October 14, 1987; accepted February 9, 1988.

Correspondence and reprint requests Jerry A. Schneider, M.D., Department of Pediatrics, M-009-F, School of Medicine, University of California, San Diego, La Jolla, CA 92093.

Supported by Grants DK 18434, AM 25548, General Clinical Research Center Grants RR 00827 and RR 00042, and Contract NO1-HD-6-2927 from the National Institutes of Health, a grant from the Generic Pharmaceutical Industry Association, and by gifts from the Bernard L. Maas Foundation, the Pharmaceutical Manufacturers Association and the Cystinosis Foundation. nephropathic cystinosis (1). Cystine accumulates in the lysosomes of children with this autosomal recessive disease due to a defect in lysosomal transport (2-6). MEA has been shown previously to effectively deplete cystine from cystinotic cells in culture, as well as leukocytes in vivo (7). MEA depletes cystine by entering the lysosome and participating in a thiol-disulfide interchange reaction to produce cysteine and cysteine-MEA mixed disulfide, both of which cross the cystinotic lysosomal membrane $(8,9)$. Several clinical trials have demonstrated the cystine-depleting effects of MEA, but small numbers of subjects and brief treatment periods have prevented firm conclusions concerning the clinical effectiveness of the drug (10-13). The recent report from the national collaborative MEA study is the first to demonstrate the long-term clinical effectiveness of MEA treatment in a large population of patients (1). Children with cystinosis have impaired growth, renal Fanconi syndrome, and glomerular deterioration, resulting in end-stage renal failure within the first decade of life. Children treated with MEA show improved growth and slowed progression of renal glomerular failure (1).

The bad taste and smell of MEA make compliance difficult for many patients. Fourteen percent of patients were withdrawn from the collaborative study for noncompliance, usually secondary to intolerance of the medication (1). MEAP, a phosphorothioester of MEA, is considered less toxic (14). Masking the thiol group also improves the smell and taste and may prevent MEAP from binding to proteins resulting in an increased amount reaching target tissues (15).

Inasmuch as the thiol group of MEA is essential to its effectiveness, MEAP must be dephosphorylated at some stage of its metabolism. The hydrolysis of MEAP to MEA occurs in many rat tissues including intestine, but not in serum $(15,16)$. Therefore, with oral administration, dephosphorylation could occur in the gut but with an intravenous dose, dephosphorylation may not occur before MEAP reaches the tissues (17). MEAP has also been shown to be effective at decreasing leukocyte cystine content in vivo, and it was postulated that the conversion of MEAP to MEA may occur intracellularly, therefore targeting the active agent to the site of cystine storage (17). The point at which MEAP is dephosphorylated after an oral dose could determine the relative effectiveness of MEAP versus MEA for treating cystinosis.

In the following study the total plasma concentration and protein-bound concentration of MEA is compared after equi- 
molar oral doses of MEA and MEAP. The effectiveness of MEAP and MEA at depleting leukocyte cystine content in vivo is also assessed. To complete a comparison of these two drugs, the taste preferences of patients taking the medication have also been evaluated.

\section{MATERIALS AND METHODS}

Subjects. Subjects for the comparison of oral MEA to oral MEAP included six children ages 2-10 yr. All of these patients had been treated with MEA before this study. The characteristics of these patients are given in Table 1 . This study complies with the guidelines of the Human Subjects Committees of the University of California, San Diego, and the University of Michigan, Ann Arbor, and the National Institutes of Health. The population of patients and parents who received questionnaires included 88 patients from 81 different families who had been previously treated with MEA.

Materials. All reagents used were of the highest quality available. MEA $\mathrm{HCl}$ was obtained from Sigma Chemical Co. (Food and Drug Division, Ltd., St Louis, MO) and prepared in the pharmacies of the University of California, San Diego, the University of Michigan, Ann Arbor, or the National Institutes of Health as an aqueous solution of $0.64 \mathrm{M}$. Phosphocysteamine was obtained from Medea Laboratories (West Hampton Beach, $\mathrm{NY}$ ) and was also prepared by the pharmacies in water to a concentration of $0.64 \mathrm{M}$.

Plasma MEA was measured using a Bioanalytical Systems (BAS, West Lafayette, IN) LCEC chromatograph with a single piston pump and a single gold/mercury electrode. A BAS biophase ODS $5 \mu \mathrm{g}(4.6 \times 250 \mathrm{~mm})$ reverse phase column was used.

Biochemical studies. Before this trial all six children stopped their usual doses of MEA. In two patients (patients 1 and 2) MEA was withheld for $24 \mathrm{~h}$ before the study and in the remaining patients it was withheld for $1 \mathrm{wk}$. Patients were admitted to the Clinical Research Center at the University of California, San Diego, the University of Michigan, Ann Arbor, or the National Institutes of Health. Solid foods were withheld for $8 \mathrm{~h}$ before the administration of the test doses but patients had free access to fluids. A baseline blood sample of $4 \mathrm{ml}$ of heparinized blood was drawn. Three $\mathrm{ml}$ were poured into an equal volume of acidcitrate dextrose solution and placed on ice for preparation of leukocytes. The remaining $1 \mathrm{ml}$ of blood was immediately centrifuged at $2500 \times g$ for $5 \mathrm{~min}$ and plasma removed and placed on ice. In two patients (patients 1 and 2) $100 \mu$ l of plasma was added to $16 \mu \mathrm{l}$ of $2 \mathrm{~N}$ perchloric acid to precipitate proteins. The proteins were separated by centrifugation and frozen for subsequent assay of protein-bound MEA. The remaining plasma was either kept on ice for immediate assay of total plasma MEA, or frozen at $-20^{\circ}$ for future analysis. At time zero, patients received an oral dose of $0.23 \mathrm{mmol} / \mathrm{kg}$ body weight of MEA or MEAP in water. Blood samples for assay of plasma MEA concentration were taken at various times for up to $6 \mathrm{~h}$. Blood for determination of leukocyte cystine content was taken at 0,1 , and $6 \mathrm{~h}$ for all patients. In patients 1 and 2 the second drug was administered $24 \mathrm{~h}$ later. In all other patients the second drug was given $48 \mathrm{~h}$ later. In one patient (patient 5) a third dose of MEA was given 4 days after the first dose, but it was given with $8 \mathrm{oz}$ of whole milk

Table 1. Characteristics of patients tested with oral MEA and $M E A P$

\begin{tabular}{cclcc}
\hline Patients & $\begin{array}{c}\text { Age } \\
(\mathrm{yr})\end{array}$ & Sex & $\begin{array}{c}\text { Wt } \\
(\mathrm{kg})\end{array}$ & $\begin{array}{c}\text { Time MEA } \\
\text { withheld (days) }\end{array}$ \\
\hline 1 & 8 & M & 21.0 & 1 \\
2 & 10 & M & 23.2 & 1 \\
3 & 2 & F & 9.7 & 7 \\
4 & 4 & M & 11.8 & 7 \\
5 & 5.5 & F & 19.5 & 7 \\
6 & 5 & M & 14.5 & 7 \\
\hline
\end{tabular}

in order to evaluate the effect of food on absorption and plasma concentration.

Analysis of samples. A mixed leukocyte preparation for determination of leukocyte cystine content was made according to the method of Greene et al. (18). Leukocyte cystine content was determined using a specific cystine binding protein (19) and total protein was determined by the method of Lowry et al. (20). The total plasma MEA concentration was determined by first treating $100 \mu 1$ of plasma with sodium borohydride to reduce all disulfides to thiols. The protein was then precipitated with trichloroacetic acid and the supernatant assayed for MEA using HPLC separation followed by electrochemical detection (21). Samples of vomitus from two patients were also reduced before high-performance liquid chromatography analysis. For determination of plasma protein-bound MEA, plasma proteins were washed with a series of organic solvents and dried. A total of $12-15 \mathrm{mg}$ of protein was dissolved in urea and reduced with sodium borohydride (22).

Questionnaire. A written questionnaire was sent to the families of all patients currently taking MEA as a part of the National Collaborative Cysteamine Study. Included in the package was a sample of MEAP to allow the child to try this drug for approximately 1 wk and decide which was preferred. In addition to drug preference the parents were also asked to evaluate how often their child vomited as a result of taking the medication.

\section{RESULTS}

Biochemical studies. Patients 1 and 2, who had not taken MEA for $24 \mathrm{~h}$ before testing, demonstrated identical plasma MEA curves after the administration of either MEA or MEAP, and leukocyte cystine was depleted similarly by both treatments (Fig. 1). Patient 3, who had not taken MEA for 1 wk before

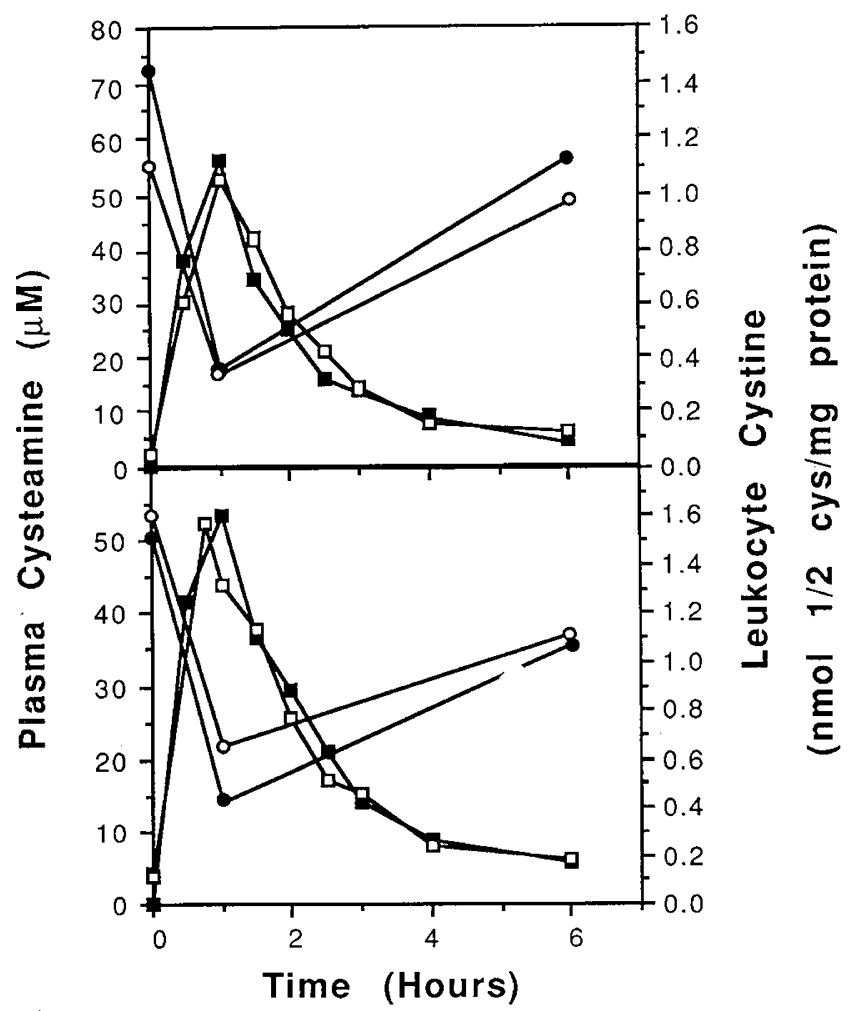

Fig. 1. Plasma MEA and leukocyte cystine content after an oral dose of MEA or MEAP in patients who had not taken MEA for $24 \mathrm{~h}$. Patient 1 (top) and patient 2 (bottom) received an oral dose $(0.23 \mathrm{mmol} / \mathrm{kg})$ of either MEA (closed symbols) or MEAP (open symbols). Blood was sampled for determination of plasma MEA $(\mathbf{\square}, \square)$ at various time intervals up to $6 \mathrm{~h}$. Leukocyte cystine $(\bullet, 0)$ was measured before and 1 and $6 \mathrm{~h}$ after drug administration. 
testing, displayed a plasma MEA peak slightly later after MEAP than after MEA (Fig. 2, top), and patient 4 exhibited a plasma MEA peak somewhat greater than MEAP than after MEA ingestion (Fig. 2, bottom). As seen in Figure 1, withdrawing MEA for $24 \mathrm{~h}$ before testing did not result in greatly elevated leukocyte cystine. Therefore the net decrease in leukocyte cystine at $1 \mathrm{~h}$ was smaller and more transitory than that seen when no MEA was taken for 1 wk (Fig. 2). After 1 wk without MEA, the leukocyte cystine was as high as 5 to $7 \mathrm{nmol} 1 / 2$ cystine/mg protein and even $6 \mathrm{~h}$ after the single MEA dose leukocyte cystine was significantly lower than the predrug value. The data from the remaining two patients was not shown in figure form because vomiting occurred in both of these patients $40 \mathrm{~min}$ after the test doses.

The peak plasma MEA concentration, the time of maximal MEA concentration, the percent decrease in leukocyte cystine, as well as the amount of the dose lost in vomit is given for all six patients in Table 2. Paired $t$ tests showed that there was no difference in either the maximal plasma MEA concentration or the percent decrease in leukocyte cystine content when MEA was compared to MEAP. The results in Table 2 and Figures 1 and 2 also illustrate that the time of peak plasma concentration does not differ significantly between these two drugs.

In the chromatography system used, MEAP did not coelute with MEA and treatment with sodium borohydride did not hydrolyze the phosphate group of MEAP. The presence of MEA, not MEAP, in plasma samples therefore suggests that MEAP is converted to MEA before it reaches the plasma. Analysis of vomitus samples from patient 5 indicates that this conversion occurs in the stomach. After a dose of MEAP in patient 5, MEA rather than MEAP was found in the vomitus. Incubation of this vomitus with acid phosphatase or incubation at $\mathrm{pH} 1$ and $37^{\circ} \mathrm{C}$,

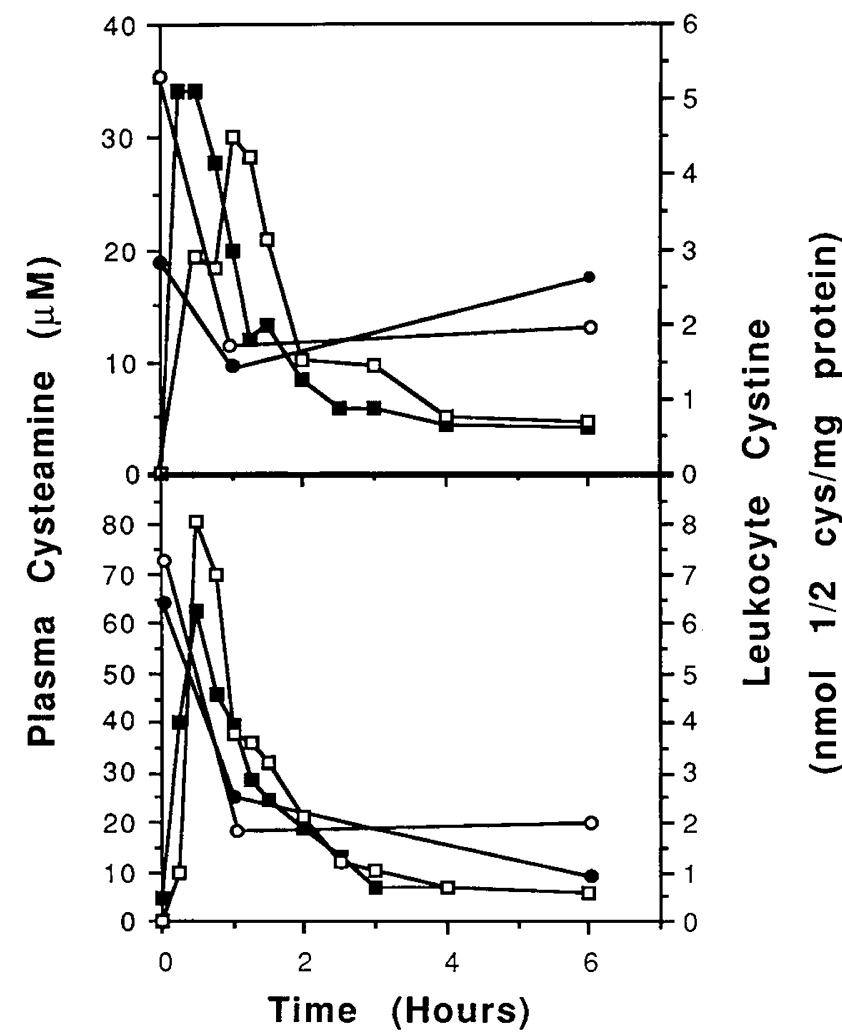

Fig. 2. Plasma MEA and leukocyte cystine content after an oral dose of MEA (closed symbols) or MEAP (open symbols) in patients who had not taken MEA for $1 \mathrm{wk}$. Patient 3 (top) and patient 4 (bottom) received an oral dose $(0.23 \mathrm{mmol} / \mathrm{kg})$ of either MEA or MEAP. Blood was sampled for determination of plasma $\operatorname{MEA}(\boldsymbol{\square}, \square)$ at various time intervals up to $6 \mathrm{~h}$. Leukocyte cystine $(\bullet, 0)$ was measured before and 1 and $6 \mathrm{~h}$ after drug administration.
Table 2. Effectiveness of oral $M E A$ and $M E A P$ at elevating plasma $M E A$ concentration and decreasing leukocyte cystine content*

\begin{tabular}{|c|c|c|c|c|c|c|c|c|}
\hline \multirow[b]{2}{*}{ Patient } & \multicolumn{2}{|c|}{$\begin{array}{l}\% \text { Dose lost } \\
\text { in vomitus }\end{array}$} & \multicolumn{2}{|c|}{$\begin{array}{l}\text { Time of peak } \\
\text { plasma MEA } \\
\text { (min) }\end{array}$} & \multicolumn{2}{|c|}{$\begin{array}{c}\text { Peak Plasma } \\
\text { MEA }(\mu \mathrm{M})\end{array}$} & \multicolumn{2}{|c|}{$\begin{array}{c}\% \text { Decrease in } \\
\text { leukocyte } \\
\text { cystine at } 60 \\
\text { min }\end{array}$} \\
\hline & MEA & MEAP & MEA & MEAP & MEA & MEAP & MEA & MEAP \\
\hline 1 & & & 60 & 60 & 56.0 & 53.2 & 75.3 & 68.8 \\
\hline 2 & & & 60 & 45 & 53.4 & 52.2 & 72.4 & 59.9 \\
\hline 3 & & & $15-30$ & 60 & 34.1 & 30.1 & 49.6 & 68.3 \\
\hline 4 & & & 30 & 30 & 62.7 & 80.9 & 60.2 & 75.1 \\
\hline 5 & 46 & 23 & 30 & 30 & 45.5 & 73.2 & 60.5 & 66.9 \\
\hline 6 & & 2 & 60 & 60 & 39.8 & 34.8 & 53.5 & 52.7 \\
\hline Mean & & & & & 48.6 & 54.1 & 61.9 & 65.3 \\
\hline$\pm \mathrm{SD}$ & & & & & \pm 10.7 & \pm 20.2 & \pm 10.2 & \pm 7.8 \\
\hline
\end{tabular}

* All patients received MEA first except patient 5 who was given MEAP on the first test day.

conditions that hydrolyse MEAP to MEA, failed to increase significantly the amount of MEA recovered in the vomitus. However, incubation of this vomitus with MEAP standard resulted in 50\% hydrolysis to MEA in $2 \mathrm{~h}$.

Inasmuch as MEA contains a free thiol group the amount bound to plasma proteins was measured in some samples from patients 1 and 2 (Fig. 3). When plasma proteins were precipitated immediately the amount of MEA bound to proteins represented only between 10 and $18 \%$ of the total plasma MEA. This percent was similar regardless of whether MEA or MEAP was given (Fig. 3 ). Because the amount bound remained relatively constant over time the percent of the total bound increased as the total plasma MEA began to decrease (Fig. 3). Protein-bound MEA is probably removed from the plasma more slowly than free MEA. The equal amount of MEA bound when MEA and MEAP are given is further evidence that MEAP is hydrolyzed by the time it reaches the plasma.

In these studies the drugs were given without food, but patients normally take MEA with milk or other foods. The effect of milk on the absorption of MEA was examined in patient 5 (Fig. 4). As is shown in Table 2, patient 5 lost $46 \%$ of the MEA dose when vomiting occurred at $40 \mathrm{~min}$. No vomiting occurred when the MEA was administered with milk, yet the peak plasma level of MEA was less than that seen when $46 \%$ of the dose was lost (Fig. 4). The curve was also broader and stayed elevated slightly longer. By $4 \mathrm{~h}$ no significant differences were seen between the curves. It was hoped that administration of MEA with food such as milk would slow the absorption of the drug and make the plasma levels stay elevated longer, creating a slow release form of administration. This occurred to some extent but not enough to alter the required frequency of drug administration.

Questionnaire. Of 88 responses 43 preferred MEAP, 34 preferred the MEA that they had been taking, and 11 were unable to tell the difference. The drug preference did not correlate with either the age at which MEA therapy was started or the length of time they had been taking MEA. Therefore, despite the feeling by physicians that patients had a great deal of difficulty taking MEA, when given a choice between MEA and MEAP only half of the children preferred MEAP. Also, the histogram of vomiting frequency (Fig. 5) illustrates that only a small number of children had a significant problem with vomiting after administration of MEA.

\section{DISCUSSION}

Before this study the only other measures of plasma MEA in children with cystinosis were done 1 and $6 \mathrm{~h}$ after a dose (23). The additional time points included herein enable some estimates of the pharmacokinetics of this drug. Inasmuch as the same measurements were not made after intravenous adminis- 


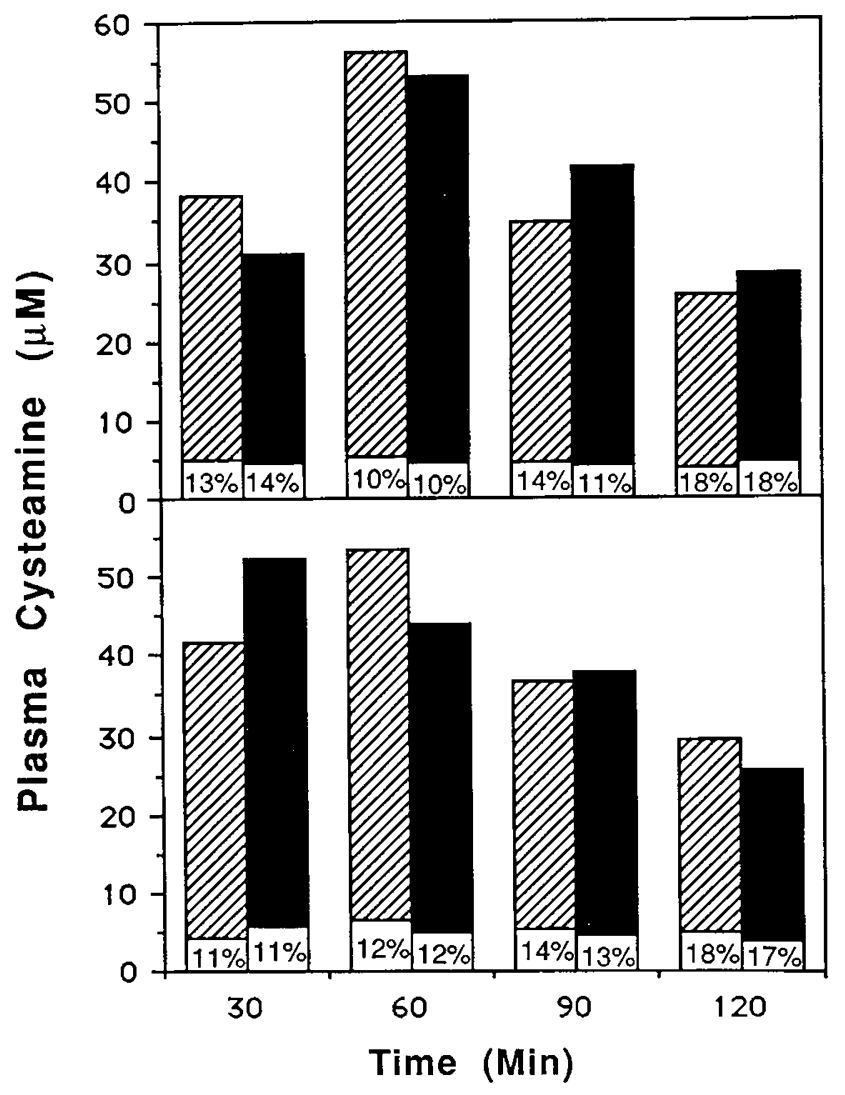

Fig. 3. Plasma MEA and plasma protein-bound MEA concentration in patient 1 (top) and 2 (bottom) after an oral dose $(0.23 \mathrm{mmol} / \mathrm{kg})$ of either MEA or MEAP. Each bar represents total plasma MEA concentration and the bottom unfilled section gives the concentration bound to plasma proteins. The numbers in each bar represent the percent of total plasma MEA that is bound to plasma proteins. Hatched bars represent MEA after an oral MEA dose and solid bars represent MEA after an oral MEAP dose.

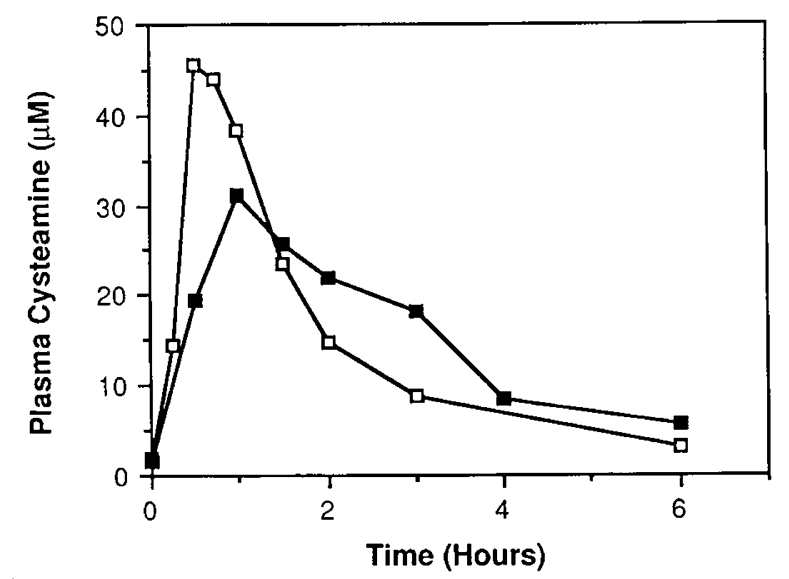

Fig. 4. The effect of milk on plasma MEA concentration over time. An oral dose of $0.23 \mathrm{mmol} / \mathrm{kg}$ of MEA was given to patient 5 with or without $8 \mathrm{oz}$ of whole milk. When milk was not given $(\square)$ vomiting occurred and $46 \%$ of the dose was lost. When administered with milk (ם) no vomiting occurred.

tration, conclusions concerning gastrointestinal absorption are difficult. Drug absorption is a complex process that is affected by the rate of gastric emptying as well as absorption of the drug from multiple intestinal sites. In these studies the time of peak plasma concentration occurred at 30-60 min after the oral dose, and significant plasma MEA was seen as early as $15 \mathrm{~min}$. This rapid appearance in the plasma suggests that at least some is

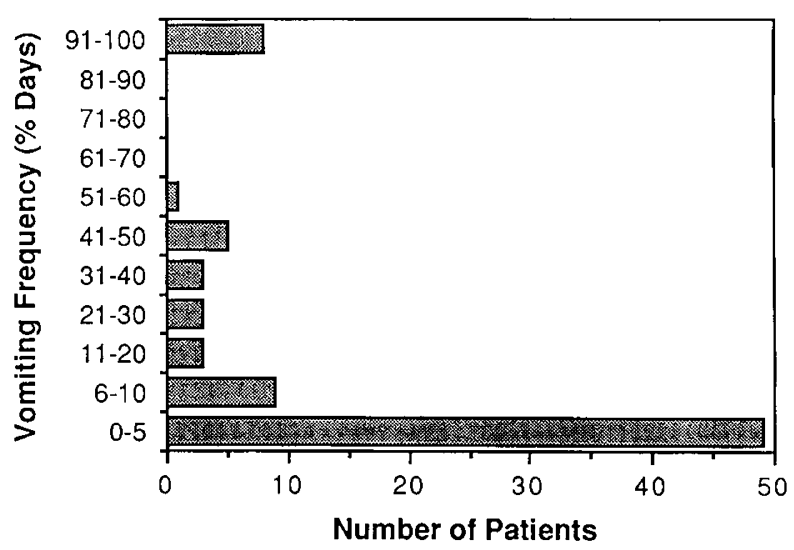

Fig. 5. Frequency that vomiting occurs in patients taking MEA. Information concerning the frequency of vomiting was collected by questionnaire from 88 patients currently taking MEA. Vomiting frequency was expressed as number of days per 100 that vomiting occurs.

being absorbed through the stomach. The peak time of 30-60 min is the same as that determined in adults by Eldjarn and Nygaard (24) using ${ }^{35}$ S-MEA.

The data accumulated from analysis of vomitus have also provided important information. In all three instances of vomiting, it occurred $40 \mathrm{~min}$ after the dose was given. It is interesting that patient 5 had a peak plasma MEA at $30 \mathrm{~min}$, yet still had enough MEA in the stomach at $40 \mathrm{~min}$ to lose $46 \%$ of the dose; whereas, patient 6 lost only about $2 \%$ of the dose in vomit at 40 min, but plasma MEA continued to increase until $60 \mathrm{~min}$. It appears that the amount of the drug absorbed through the stomach, the rate it leaves the stomach, and the rate of absorption in the intestines varies considerably from patient to patient. Also, the hydrolysis of MEAP proceeded relatively slowly when it was incubated with vomitus in vitro (50\% hydrolysis in $2 \mathrm{~h})$, whereas complete hydrolysis of an MEAP dose occurred in the stomach in $40 \mathrm{~min}$. This suggests that some cleavage of the phosphate group may be occurring at sites, such as membranes, that are not available during in vitro incubations.

The rate at which MEA disappears from the plasma is also rapid. By $2 \mathrm{~h}$ plasma MEA had decreased to less than half its maximal concentration, and by $6 \mathrm{~h}$ it had almost completely disappeared. It is not known whether MEA is being taken up directly into cells and lysosomes or rapidly bound to other proteins. Herein an estimate of the percent dose present in the plasma at the maximal concentration reveals that it represents only about $1-2 \%$ of the dose. Fecal losses of MEA have not been determined and urinary losses are small $(7,23)$. It is more likely. that the small percent of MEA in plasma is due to rapid uptake by cells and binding to proteins than to poor absorption or urinary excretion.

It is surprising how little of the total plasma MEA was bound to plasma proteins in our study $(10-18 \%)$. During in vitro incubations of MEA with plasma about $80 \%$ was bound after 1 $\mathrm{h}$ at $37^{\circ} \mathrm{C}$ and $95 \%$ by $4 \mathrm{~h}$. Thiol compounds such as cysteine and homocysteine readily bind to plasma proteins $(22,25)$. In man it has been determined that about $50 \%$ of total plasma cyst(e)ine is protein bound (25). Intraperitoneal injections of ${ }^{35} \mathrm{~S}$ MEA into mice found about $1.5 \%$ of the dose in the plasma and of this about one-third was bound to proteins (26). More information is needed to confirm the amounts of MEA bound to proteins in vivo over a broader time span and to determine how well it competes with other thiols for binding sites. However, the fact that equal amounts of MEA were bound to plasma proteins regardless of whether MEA or MEAP was given, indicate that the theory that the phosphate group will prevent binding to proteins and allow the compound to be targeted to the lysosome does not apply when MEAP is given orally. It may, however, occur when MEAP is given intravenously. 
Despite the bad taste of MEA many patients have become accustomed to it and have no difficulty taking it. This conclusion may be somewhat biased by the fact that the parents who responded to the questionnaire are those who tolerated MEA well enough to participate in the National Collaborative Cysteamine Study. Another possibility is that most patients are so convinced that MEA is helping their child that they may be afraid to make any changes in medication. Perhaps one reason that MEAP was not the universal choice is that it is not completely odorless and tasteless. When made fresh a $0.64 \mathrm{M}$ solution of MEAP contained $0.6 \% \mathrm{MEA}$. When stored at $4^{\circ} \mathrm{C}$ this remained stable for about $3 \mathrm{wk}$. By $8 \mathrm{wk}$ the percent contamination was $1.1 \%$ and by 12 wk it had increased to $1.5 \%$.

Along with MEA therapy, children with cystinosis are treated symptomatically for the loss of fluids and electrolytes, and receive kidney transplants when end-stage renal failure occurs (2). Individuals who received renal transplants are now reaching their late 20 s and early 30 s and are beginning to show the effects of prolonged cystine accumulation in tissues other than the kidney. A recent survey of 80 patients more than $10 \mathrm{yr}$ of age revealed that almost $75 \%$ of these patients required thyroid replacement, $27 \%$ had splenomegaly, $42 \%$ had hepatomegaly, $86 \%$ had photophobia, $32 \%$ had decreased visual acuity, and $15 \%$ had corneal ulcerations (27). Nine of 80 patients had central nervous system abnormalities that ranged from speech difficulties to severe impairments of swallowing and walking (27). Cerebral atrophy has also been observed on computerized axial tomography $(28,29)$. The progressive involvement of tissues other than the kidney emphasizes the need for continuous aggressive treatment.

Plasma MEA has been measured in two older patients after an oral MEA dose. In a 22-yr-old patient who had not previously received MEA a $0.154 \mathrm{mmol} / \mathrm{kg}$ dose of MEA resulted in a peak plasma MEA level of $82 \mu \mathrm{M} 30 \mathrm{~min}$ after the dose. Before the dose leukocyte cystine was $13.8 \mathrm{nmol} 1 / 2$ cystine/mg protein. By $60 \mathrm{~min}$ the cystine content had decreased to $5.8 \mathrm{nmol} 1 / 2$ cystine/ $\mathrm{mg}$ protein and at $6 \mathrm{~h}$ leukocyte cystine had not begun to increase $(2.9 \mathrm{nmol} 1 / 2$ cystine $/ \mathrm{mg}$ protein). In a 20 -yr-old patient who received an oral dose of only $0.08 \mathrm{mmol} \mathrm{MEA} / \mathrm{kg}$ body weight plasma MEA reached $43 \mu \mathrm{M} 30$ min after administration of the drug. This patient had taken MEA in the past but had not been receiving the drug for the past year. Leukocyte cystine content was reduced from $5.9 \mathrm{nmol} 1 / 2$ cystine $/ \mathrm{mg}$ protein before the dose to $2.6 \mathrm{nmol} 1 / 2$ cystine $/ \mathrm{mg}$ protein at $1 \mathrm{~h}$. By $6 \mathrm{~h}$ leukocyte cystine had increased to $5.1 \mathrm{nmol} 1 / 2$ cystine $/ \mathrm{mg}$ protein in this patient. These results indicate that lower per $\mathrm{kg}$ doses of MEA in older patients yield plasma MEA levels comparable to those seen in younger patients receiving higher per $\mathrm{kg}$ doses. As more older (and larger) patients receive this drug, it may be wise to express the dose in terms of body surface area rather than body weight.

Before renal transplantation most patients undergo peritoneal dialysis. Plasma samples and peritoneal dialysis samples obtained from a 19-yr-old patient revealed that plasma MEA was still 18 $\mu \mathrm{M} 6 \mathrm{~h}$ after an oral MEA dose of $0.147 \mathrm{mmol} / \mathrm{kg}$ body weight. MEA, totaling $11 \mathrm{nmol}$, was lost in a 1-h dialysate collected $8 \mathrm{~h}$ after an oral MEA dose. Therefore, there is some loss of MEA in dialysis fluid but because MEA is still significantly elevated at $6 \mathrm{~h}$ it is possible the losses in dialysis fluid are smaller than normal kidney losses which have been estimated at $1-2 \%$ of the dose (23).

The results of this study indicate that when taken orally, MEA and MEAP can be treated as equivalent and should be equally effective for the treatment of cystinosis. Any differences in treatment effectiveness are likely due to differences in compliance rather than to biochemical differences between the two compounds. The taste preferences of the children indicate a slight preference for MEAP, but the difference was not as striking as expected.

Acknowledgments. The authors thank Eric Marcusson and Dewaine Jackson for their excellent technical assistance, and the
Clinical Research Center staff, University of California, San Diego and Juliette Urtis, Nurse Clinician, Pediatric CRC, University of Michigan, Ann Arbor for help in collecting blood samples.

\section{REFERENCES}

1. GahI WA, Reed GF, Thoene JG, Schulman JD, Rizzo WB, Jonas AJ, Denman DW, Schlesselman JJ, Corden BJ, Schneider JA 1987 Cysteamine therapy for children with nephropathic cystinosis. N Engl J Med 316:971-977

2. Schneider JA, Schulman JD 1986 Cystinosis and the Fanconi Syndrome. In: Andreoli TF, Hoffman JF, Fanestil DD, Schultz SG (eds) Physiology of Membrane Disorders. Plenum Publishing Corp, New York, pp 985-997

3. Gahl WA, Bashan N, Tietze F, Bernardini I, Schulman JD 1982 Cystine transport is defective in isolated leukocyte lysosomes from patients with cystinosis. Science 217:1263-1265

4. Gahl WA, Tietze F, Bashan N, Steinherz R, Schulman JD 1982 Defective cystine exodus from isolated lysosome-rich fractions of cystinotic leukocytes. J Biol Chem 257:9570-9575

5. Jonas AJ, Smith ML, Schneider JA 1982 ATP-dependent lysosomal cystine efflux is defective in cystinosis. J Biol Chem 257:13185-13188

6. Jonas AJ, Smith ML, Allison WS, Laiking PK, Greene AA, Schneider JA 1983 Proton-translocating ATPase and lysosomal cystine transport. J Biol Chem 258:11727-11730

7. Thoene JG, Oshima RG, Crawhall JC, Olson DL, Schneider JA 1976 Cystinosis: intracellular cystine depletion by aminothiols in vitro and in vivo. J. Clin Invest 58:180-189

8. Gahl WA, Tietze F, Butler JB, Schulman JD 1985 Cysteamine depletes cystinotic leucocyte granular fractions of cystine by the mechanism of disulfide interchange. Biochem J 228:545-550

9. Pisoni RL, Thoene JG, Christensen HN 1985 Detection and characterization of carrier-mediated cationic amino acid transport in lysosomes of normal and cytinotic human fibroblasts. Role in therapeutic cystine removal? J Biol Chem 260:4791-4978

10. Yudkoff M, Foreman JW, Segal S 1981 Effects of cysteamine therapy in nephropathic cystinosis. N Engl J Med 304:141-145

11. Da Silva VA, Zurbrügg RP, Lavanchy P, Blumberg A, Suter H, Wyss SR, Lüthy CM, Oetliker OH 1985 Long-term treatment of infantile nephropathic cystinosis with cysteamine. N Engl J Med 313:1460-1463

12. Girardin EP, De Wolfe MS, Crocker JFS 1979 Treatment of cystinosis with cysteamine. J Pediatr 94:838-840

13. Louis J-J, Guibaud P, Dumoulin R, Parchoux B, Zabot M-T, Bureau J, Baltassat P, Frederich A, Larbre F 1984 La cysteamine dan le traitement de la cystinose infantile etudes in vitro et in vivo. Pediatrie 34:619-633

14. Yuhas JM 1980 On the potential application of radioprotective drugs in solid tumor radiotherapy. In: Sokol GH, Maickel RP (eds) Radiation-Drug Interactions in the Treatment of Cancer. John Wiley \& Sons, Inc, New York, pp 113-135

15. Shapiro B, Kollmann G, Martin D 1970 Mechanism of action of radiation protective agents: in vivo distribution and metabolism of cysteamine-Sphosphate (MEAP). Radiat Res 44:421-433

16. Herrington KA, Small CJ, Meister A, Friedman OM 1967 Studies on latent derivatives of aminoethanethiols as potentially selective cytoprotectants. IV Enzymatic hydrolysis of cysteamine-S-phosphate. Cancer Res 27:148-151

17. Thoene JG, Lemons R 1980 Cystine depletion of cystinotic tissues by phosphocysteamine (WR638). J Pediatr 96:1043-1044

18. Greene AA, Jonas AJ, Harms E, Smith ML, Pellet OL, Bump EA, Miller AL, Schneider JA 1985 Lysosomal cystine storage in cystinosis and mucolipidosis type II. Pediatr Res 19:1170-1174

19. Oshima RG, Willis RC, Furlong CE, Schneider JA 1974 Binding assays for amino acids. The utilization of a cystine binding protein from Escherichia coli for the determination of acid-soluble cystine in small physiological samples. J Biol Chem 249:6033-6039

20. Lowry OH, Rosebrough NJ, Farr AL, Randall RJ 1951 Protein measurement with the Folin phenol reagent. J Biol Chem 193:265-275

21. Smolin LA, Schneider JA Measurement of total plasma cysteamine using highperformance liquid chromatography with electrochemical detection. Ana Biochem (168:374-379)

22. Smolin LA, Benevenga NJ 1982 Accumulation of homocyst(e)ine in vitamin B- 6 deficiency: a model for the study of cystathionine $\beta$-synthase deficiency. J Nutr 112:1264-1272

23. Jonas AJ, Schneider JA 1982 Plasma Cysteamine concentrations in children treated for cystinosis. J Pediatr 100:321-323

24. Eldjarn L, Nygaard O 1954 Cysteamine-cystamine: Intestinal absorption, distribution among various organs and excretion. Arch Int Physiol 62:476486

25. Malloy MH, Rassin DK, Gaull GE 1981 A method for measurement of free and bound plasma cyst(e)ine. Anal Biochem 113:407-415

26. Eldjarn L, Pihl A 1956 On the mode of action of X-ray protective agents I. The fixation in vivo of cystamine and cysteamine in proteins. J Biol Chem 223:341-35

27. Gahl WA, Schneider JA, Thoene JG, Chesney R 1986 Course of nephropathic cystinosis after age 10 years. J Pediatr 109:605-608

28. Ehrich JHH, Stoepple L, Offner G, Brodehl J 1979 Evidence for cerebral involvement in nephropathic cystinosis. Neuropadiatrics 10:128-137

29. Jonas AJ, Conley SB, Marshall R, Johnson RA, Marks M, Rosenberg H 1987 Nephropathic cystinosis with central nervous system involvement. Am J Med 83:966-970 